\title{
Redes de cooperação entre pequenas empresas do setor hoteleiro e a rede turística: um estudo de casos múltiplos em Aracaju, Sergipe
}

\author{
Cooperation networks between small hospitality \\ firms and the tourism network: a multiple case \\ study in Aracaju, Sergipe
}

\author{
Aline Cedraz de Cerqueira' \\ Patrícia Melo Sacramento ${ }^{2}$ \\ Rivanda Meira Teixeira ${ }^{3}$
}

RESUMO

Este estudo tem como objetivo geral analisar como empresas hoteleiras de pequeno porte utilizam-se da rede de cooperação para garantir a participação no mercado. Pretende, especificamente, observar como ocorreu a formação da rede de cooperação entre as empresas do setor hoteleiro e as demais da rede turística, identificar o papel desempenhado por aquelas que participam da rede e relatar os principais benefícios percebidos pelos participantes da rede. Assim, foram escolhidos para o estudo dois hotéis de mesmo porte, localizados na orla da cidade de Aracaju, que atuam em cooperação com outras empresas da rede turística. Com base na análise dos dois casos, foi possível identificar uma atitude positiva dos empresários/gestores dos hotéis com relação ao trabalho em redes de cooperação com o intuito de compartilhar recursos e informações para que assim possam alcançar seu principal escopo: o aumento da demanda turística do estado e a sobrevivência em mercado tão competitivo.

1 Graduanda do Curso de Administração da Universidade Federal de Sergipe. Área de interesse em pesquisa: Empreendedorismo e Gestão em Turismo. aninicedraz@yahoo.com.br.

2 Graduanda do Curso de Administração da Universidade Federal de Sergipe. Área de interesse em pesquisa: Empreendedorismo e Gestão em Turismo. pathy_csl@hotmail.com

3 Professora do Departamento em Administração e do Mestrado em Economia (NUPEC) da Universidade Federal de Sergipe. Doutora em Administração pela Cranfield University - Inglaterra (1996). Pós Doutorado em Gestão Turismo na Bournemouth University, Inglaterra e na Strathclyde University - Escócia (2000-200I). Pós Doutorado em Empreendedorismo em Turismo na HEC em Montreal, Canadá (2007). Área de interesse em pesquisa: Empreendedorismo e Pequenos Negócios, Gestão em Turismo. rivandateixeira@terra.com.br 
Palavras-chave: redes de cooperação, setor hoteleiro, rede turística, pequenas empresas

\section{ABSTRACT}

The objective of this study is to analyze how small hospitality firms use of cooperation networks to guarantee its participation in the market. Specifically intents, to analyze the formation of the network between firms of this sector and other members of the tourism network, to identify the role played for the companies and to tell the main benefits perceived for the participants of this net. Two hotels of the same size located on Aracaju beach that act in cooperation with other companies had been chosen for the study. On the basis of the analysis of the two cases, was possible to identify a positive attitude of the entrepreneurs/managers of the hotels with regard to the cooperation network with intention to share resources and information so that thus they can reach its main objective: the increase of the tourist demand of the State and its survival in a competitive market.

Key-words: cooperation networks, hospitality sector, tourism network, small firms 


\section{INTRODUÇÃO}

O setor do turismo destaca-se em função de seu notável crescimento no contexto econômico, tanto no Brasil, quanto no mundo. Segundo o Serviço de Apoio às Micro e Pequenas Empresas - SEBRAE (2005) - , o turismo é o setor de maior e de mais sólida ascensão econômica, apresentando uma taxa de crescimento que supera a do PIB mundial. A atividade turística deve crescer $7,5 \%$ ao ano, nos próximos dez anos, movimentando cerca de U\$ 3,4 trilhões (I0,9\% do PIB mundial).

O Brasil também vem apresentando crescimento expressivo no setor turístico. Segundo Jean-Claude Baumgarten, presidente do World Travel and Tourism Council WTTC (2008) -, é, atualmente, o I4.ffl país no ranking mundial da economia de turismo; o que representa um avanço, já que, em 2007, ocupava a i8.ffi posição. Esse crescimento se faz importante na medida em que o setor traz desenvolvimento econômico e geração de novos empregos ao País.

O setor turístico caracteriza-se por abrigar um extenso número de atividades econômicas, entre as quais se destacam aquelas voltadas para a exploração de alojamentos, restaurantes, transportes, lazer e agências de viagem. Segundo Santos (2007), a interação entre as empresas que atuam nesse segmento é de fundamental importância, visto que seria praticamente impossível alcançarem seus objetivos agindo de forma isolada. A formação de redes de cooperação, portanto, torna-se uma estratégia indispensável para atender à crescente demanda turística e às exigências de um público que cada dia se torna mais multifacetado.

A formação de redes de cooperação entre empresas que compõem a rede turística e as que integram o setor hoteleiro permite, especialmente aos hotéis, obter vantagens competitivas, tornando-os mais eficientes e facilitando o alcance de seus objetivos.

Redes são formas articuladas e permitem que empresas distintas trabalhem mutuamente de maneira organizada. Por meio delas, soluções poderão ser encontradas e disseminadas, novos conhecimentos podem ser produzidos, estimulando, assim, o desenvolvimento das diversas organizações que atuam em parceria (MINISTÉRIO DO TURISMO, 2007).

A realização deste estudo em Sergipe justifica-se pelo crescimento alcançado pelo setor turístico no estado, nos últimos anos, com impactos bastante positivos no cenário econômico da capital. É importante ressaltar que Aracaju tem uma combinação perfeita para o desenvolvimento do turismo: praias, sol, boa comida, passeios agradáveis e tranquilidade. Segundo a Embratur (2009), observa-se que a atividade turística em Sergipe cresceu $4,7 \%$ de janeiro a outubro de 2008 ao comparar-se com o mesmo período de 
2007. Nesse cenário, destaca-se o desenvolvimento do turismo de negócios, o qual, de acordo com a Associação Brasileira da Indústria de Hotéis em Sergipe — Abih/SE (2008) —, é um dos segmentos que mais tem crescido.

Este estudo tem, portanto, como objetivo geral analisar como as empresas hoteleiras de pequeno e médio porte utilizam-se de rede de cooperação para garantir a participação no mercado. Pretende, especificamente, observar como ocorreu a formação da rede de cooperação entre empresas do setor hoteleiro e demais da rede turística, identificar o papel desempenhado pelas que participam da rede, bem como as suas principais características, e relatar os principais benefícios percebidos pelos participantes da rede.

\section{Redes De PEQUENAS EMPRESAS}

Em função das mudanças na economia mundial, as organizações passam por grandes modificações e novas exigências. Dessa forma, surge a necessidade de articular-se a fim de aliar interesses em comum, em busca da solução de problemas e da manutenção dos negócios. As empresas, ao se reunirem, têm ciência de que seria praticamente impossível alcançar seus objetivos atuando de forma isolada.

Para Becker e Basil (2006), o estudo de redes não é recente; vêm sendo exploradas por diversos autores, em razão do grande destaque na integração entre as pequenas empresas, ao passo que são estabelecidas como uma estratégia de desenvolvimento socioeconômico regional e local.

Mesmo com o crescente estudo sobre rede, não é possível defini-la de forma exata em razão da fragmentação e da complexidade de conceitos. De forma geral, Ferreira e Teixeira (2007) destacam que as redes de empresas são fundamentadas em formato organizacional, utilizando tipos inovadores de alianças, o que permite combinar informalidade, espontaneidade e eficácia, desfazendo modelos rigorosos de organização. Segundo Batista e Oliveira (200I), uma rede é estabelecida com base em interações de organizações e de indivíduos, os quais têm, na maioria das vezes, interesses conflitantes, sendo, assim, intricado o alcance de objetivos comuns.

A formação de redes entre as pequenas empresas, na visão de Balestrin, Reves e Verschoore (2008), não está fundamentalmente condicionada a que estejam na mesma localidade, ou seja, o aprendizado recíproco e a inovação coletiva têm a capacidade de ocorrer mesmo não existindo agrupamento de empresas.

Segundo Amato Neto (2000), as redes constituem um conjunto de empresas que têm como objetivo principal o fortalecimento das atividades de cada componente, que se completa, tanto nos aspectos técnicos, quanto nos administrativos. Vale lembrar que o relacionamento entre as empresas pode ter prazo indeterminado e aberto a novos participantes. 
As empresas de pequeno porte, em decorrência da maior competitividade dos mercados, encontram diversas dificuldades em atuar de forma sólida. Por essa razão, surge como alternativa para se manterem no sistema a formação de redes de cooperação, as quais são consideradas como um adequado meio para que sobrevivam e compitam com grandes empresas em diversos setores (FERREIRA e TEIXEIRA, 2007).

Segundo a Secretaria do Desenvolvimento e dos Assuntos Internacionais - SEDAI (2004) - , a formação de redes admite a realização de ações ligadas que servem de facilitadoras para a solução de problemas corriqueiros. Entre os diversos benefícios proporcionados por esse sistema, podem-se destacar melhorias nas negociações, troca de serviços, aprendizagem, etc. Uma pequena empresa não tem totais condições de dominar tudo aquilo que envolve a cadeia produtiva, prejudicando assim a sua competitividade em um setor; entretanto, com a formação de redes, passam a dispor da probabilidade de compartilhamento e de cooperação na implementação de atividades (FERREIRA e TEIXEIRA, 2007).

De acordo com Ferreira, Passador e Passador (2006), existem três características básicas que fazem referência às redes: a dependência, ou seja, tudo que está envolvido em uma rede depende dos recursos de outros atores para que os objetivos sejam alcançados; o processo, pelos quais as ações na rede resultam da influência mútua dos vários atores; a institucionalização, em que as afinidades entre todos os envolvidos criam padrões de relação, até certo ponto, constantes.

Segundo Cândido (2005), existem duas abordagens de redes organizacionais, uma que se refere à busca pela compreensão do comportamento de mercados diferentes, procurando o conhecimento do ambiente externo, como princípio orientador, e outra referente à capacidade de organização de atividades econômicas.

Assim, as redes satisfazem um fenômeno organizacional que exprime a complexidade dos empreendimentos atuais, utilizando-se da flexibilidade ajustada pelas tecnologias de comunicação e incorporando estilos de gestão os quais buscam grande integração, participação e compromisso de todos os envolvidos (MIGUELLETO, s.d.).

De acordo com Laniado e Baiardi (2003), a cooperação é percebida como conjunto de recursos estruturados por meio de redes. Hoffmann, Molina-Morales e Martínez-Fernandez (2004) indicam que as motivações para a formação de uma rede podem ser variadas: complexidade de produtos, compartilhamento de conhecimentos, aprendizagem organizacional e disseminação da informação, confiança e cooperação, e defesa contra a incerteza.

Segundo Carrão (2004), em uma rede de cooperação existe maior ênfase no enfoque coletivo em detrimento do individual. A complexidade de uma rede origina-se da necessidade de facilitar a comunicação entre os membros e da tentativa de tornar compatíveis os objetivos da rede com os de seus componentes. Segundo Farias Filho, Castanha e Porto (I999), um dos objetivos comuns de uma rede de cooperação é a sobrevivência das 
empresas que compõem o grupo.

Entre os ganhos possibilitados pela cooperação, Amato Neto (2000) destaca uma série de 'necessidades' que pode ser atendida com a formação das redes de cooperação: combinar competências; compartilhar conhecimentos; partilhar riscos e custos de explorar novas oportunidades; oferecer uma linha de produtos de qualidade superior e mais diversificada; desfrutar de maior poder perante o mercado de modo a aumentar a força competitiva; e compartilhar recursos que estão sendo subutilizados.

\section{REDES DE COOPERAÇÃo ENTRE AS EMPRESAS DO SETOR HOTELEIRO}

\section{E AS DO SETOR TURÍSTICO}

Alojamento, alimentação, atividades voltadas ao lazer, comércio varejista são algumas das atividades que integram o setor turístico. Em razão da grande diversidade, explica Santos (2007), seria impraticável para uma empresa que atua de forma isolada conseguir atender com qualidade às necessidades dos clientes que compõem o produto turístico. Tendo em vista a complexidade de atividades, as empresas turísticas, sobretudo aquelas do ramo hoteleiro, vêm formando redes de cooperação e unindo esforços para que, dessa forma, melhor aproveitem as oportunidades e reduzam os riscos, facilitando o alcance de seus objetivos.

Para Donaire et al. (2009), uma rede bem organizada faz com que a capacidade competitiva do turismo local apresente melhoras expressivas, uma vez que, por meio do grupo, estratégias diferenciadas podem ser traçadas, possibilitando, assim, o alcance de vantagem competitiva. Além disso, com as redes, verifica-se também uma redução nos custos operacionais, um maior poder de negociação com os fornecedores e melhorias nos processos de vendas, distribuição e compartilhamento de informações.

De acordo com Hocayen-da-Silva e Teixeira (2009), os relacionamentos entre as organizações surgem como uma estratégia, a qual permite que as organizações do setor hoteleiro obtenham vantagens competitivas em relação aos concorrentes, tornando-as mais eficientes, reduzindo assim os impactos da ação das grandes redes do ramo no mercado.

Por meio do estudo realizado por esses autores em empresas do setor hoteleiro de Curitiba, observou-se que os relacionamentos interorganizacionais podem apresentar-se de formas distintas. Em um dos hotéis analisados, a relação é bem reduzida, não existindo cooperação com outras empresas do setor turístico. Nesse hotel, a única ligação com outros empreendimentos hoteleiros ocorre apenas no momento em que o hotel está com todos os leitos ocupados e precisa alojar alguns hóspedes. Já em outros hotéis, observouse uma maior articulação do setor, com uma grande conscientização na busca de parcerias e alianças entre coirmãos e demais empresas do setor. (HOCAYEN-DA-SILVA e 


\section{TEIXEIRA, 2009).}

De acordo com esses autores, a resistência à formação de redes no setor hoteleiro é explicada, na maioria dos casos, pela competitividade do setor e pelo comportamento individualista dos gestores organizacionais, que pensam apenas nos lucros individuais. Do outro lado, entretanto, algumas empresas hoteleiras vêm estabelecendo alianças, apresentando resultados positivos em função da troca de experiências, recursos e conhecimento.

Para Curtis e Hoffmann (2009), relacionamentos interorganizacionais na hotelaria são considerados uma opção viável de concorrência, uma vez que, para competir em situação de igualdade, é de fundamental importância a prestação de um bom serviço, o que exige interações com clientes, fornecedores e complementadores como recurso dinamizador.

\section{Contexto do setor hoteleiro}

O setor turístico vem apresentando crescimento expressivo, sendo responsável pela geração de milhões de empregos e renda. De acordo com Petrocchi (2007, p.I), "o produto turístico é constituído por três serviços básicos: transporte, hospedagem e atrativo da viagem”. Entre esses serviços destaca-se o de hospedagem, o qual é prestado pelas empresas de hotelaria, que são responsáveis pela exploração e administração dos meios de hospedagem.

Os meios de hospedagem são quase tão antigos quanto a própria civilização. As primeiras hospedarias surgiram na Grécia Antiga, com o advento dos jogos olímpicos, tendo sequência nas viagens com finalidades religiosas e nas guerras para conquistar novas terras (CÂNDIDO E VIERA, 2003). Segundo a Empresa de Turismo - ETUR (2005) - , as primeiras hospedarias com o propósito exclusivamente comercial foram tabernas e pousadas, surgidas na Idade Média.

Atualmente, segundo a Associação Brasileira de Indústria de Hotéis — ABIH (2009) —, o parque hoteleiro nacional dispõe aproximadamente de 25 mil meios de hospedagem, sendo I8 mil hotéis e pousadas. No geral, 70\% são empreendimentos de pequeno porte, o que representa mais de um milhão de empregos e a oferta de aproximadamente um milhão de apartamentos em todo o País.

Para Nunes (2009), a retomada do crescimento, prevista com o maior funcionamento do turismo, até o ano de 2020, que movimentará cinco bilhões de dólares por dia em todo mundo, deve gerar, na indústria hoteleira, grande promessa de contratação nos próximos anos, especialmente, no Brasil.

Segundo entrevista realizada pelo site Administradores.com, com a diretora 
regional da universidade suíça, Hotel Institute Montreux - HIM - Daiane Lagger, “o setor hoteleiro está otimista e espera uma grande melhora a partir de 2010 . Isso irá exigir uma grande demanda por mão de obra especializada e vai gerar grandes oportunidades de carreira em quase todos os países do mundo". Outro dado relevante que faz referência ao potencial de empregos no setor hoteleiro é a construção, realizada atualmente, de 120 hotéis.

De acordo com dados divulgados pela Secretaria de Estado do Planejamento, Habitação e do Desenvolvimento Urbano (SEPLAN), em 2007, empresas do setor turístico, destinadas a alojamento e alimentação, vêm-se expandindo gradativamente ano a ano, apresentando um crescimento de 5,1\%. Esse crescimento ocorre em decorrência de investimentos públicos e privados no setor. Além desses dois segmentos, o setor de transporte também vem apresentando crescimento significativo. Tal expansão se deve ao crescimento do turismo de Sergipe.

Nos últimos anos, Sergipe desenvolve-se, no que se refere ao setor hoteleiro, segundo a Empresa Sergipana de Turismo - EMSETUR (2008). A taxa de ocupação média dos hotéis de Sergipe, no ano de 2008 , foi de 59,9\%, mostrando um aumento de $12,31 \%$ no período de 2005 a 2008.

Após a apagada abertura do ano 2009 e dos poucos registros de ocupação durante o primeiro semestre, o setor hoteleiro em Sergipe começou a dar indícios de recuperação no segundo semestre. Um bom exemplo da possível reerguida do setor no estado foi o registro da ocupação dos hotéis no feriado de sete de setembro em que a ocupação chegou a mais de $90 \%$ em alguns hotéis da capital e aos I00\% em pousadas (JORNAL DE TURISMO, 2009). 


\section{Metodologia}

O presente estudo caracteriza-se por ser de natureza qualitativa. O método de pesquisa adotado foi o estudo de caso, isto é, de múltiplos casos, uma vez que se estudaram duas organizações. De acordo com Yin (200I, p.I9), o método do estudo de caso é indicado “quando se colocam questões do tipo 'como' e 'por quê', quando o pesquisador tem pouco controle sobre os eventos e quando o foco se encontra em fenômenos contemporâneos inseridos em algum contexto da vida real".

Para o trabalho, foram escolhidos dois hotéis do mesmo porte (três estrelas) localizados na orla da cidade de Aracaju e que atuam em cooperação com outras empresas da rede turística. A escolha baseou-se no critério de acessibilidade — facilidade de acesso a eles — e tipicidade - seleção de elementos representativos na população (LAKATOS e MARCONI, I99I).

As principais fontes de evidência foram entrevistas, análise de documentos, tais como o histórico das empresas e as informações encontradas no site dos hotéis. Nas entrevistas, utilizou-se um roteiro de entrevistas semiestruturado, o que permitiu aos entrevistados uma maior flexibilidade nas respostas. De acordo com Barros e Lehfeld (1986) e Lakatos e Marconi (I99I), a entrevista semiestruturada é aquela em que o entrevistador segue um roteiro previamente estabelecido e, caso haja necessidade durante o desenvolvimento, incluem-se novas questões. É uma ferramenta de levantamento de dados que proporciona aos pesquisadores algumas vantagens, como maior flexibilidade, oportunidade de observar atitudes e reações e de obter dados relevantes e precisos.

Em cada caso, realizou-se uma única entrevista. No hotel X, fez-se a entrevista com o proprietário e, no hotel Y, com o gerente geral. Os entrevistados foram escolhidos por terem as informações que possibilitariam o alcance do objetivo da pesquisa, sem a necessidade de realização de outras entrevistas. Para melhor compreensão dos relatos dos entrevistados, no decorrer da análise do caso, são eles referenciados no texto da seguinte forma: i) Gerente geral — GO e ii) Sócio proprietário — SP.

O roteiro de entrevistas foi composto por cinco blocos de questões: no primeiro, descreveram-se as características dos entrevistados; no segundo, colocaram-se as informações gerais sobre as empresas; no terceiro, nomeou-se a origem da rede de cooperação no setor; no quarto, declararam-se as características das empresas que participam da rede e o papel desempenhado por elas e, por fim, no quinto bloco, mencionaram-se os benefícios percebidos pelos participantes da rede de cooperação.

Após a coleta de dados, efetuou-se a transcrição da entrevista e, em seguida, procedeu-se à análise de conteúdo de forma sistemática e objetiva, buscando levantar as informações necessárias ao desenvolvimento do trabalho, tendo-se como elemento norteador os objetivos propostos. 
Neste estudo, entendeu-se rede turística como todas as empresas que atuam no setor, as associações e o governo, por meio de seus órgãos representativos que, em Sergipe, são a Empresa Sergipana de Turismo (EMSETUR) e a Fundação Municipal de Cultura Turismo e Esportes (FUNCAJU).

\section{ANÁLISES dOS CASOS}

Os dois casos serão apresentados a seguir com uma breve descrição da empresa, do entrevistado e das categorias analíticas consideradas no estudo: o papel desempenhado e os benefícios percebidos pela atuação em rede.

\section{G.1 O caso do Hotel X}

O primeiro caso a ser descrito é o do Hotel X, no qual se entrevistou o sócio proprietário do hotel, que tem 48 anos e é pós-graduado em Marketing Empresarial. Apesar de operar no hotel há apenas I (um) ano, demonstra bastante experiência no setor hoteleiro, já que atua há 15 anos nessa atividade.

O hotel situa-se na orla de Atalaia, em Aracaju, próximo à Passarela do Caranguejo, onde se concentra a maior parte dos bares; por isso é considerado um ponto turístico bem característico da cidade. Conta com 22 funcionários e 47 leitos. Foi inaugurado há I (um) ano e suas acomodações são do tipo 3 (três) estrelas - divididas em luxo, com vista para o mar com ou sem varanda e executivo lateral, capaz de comportar até quatro pessoas. Além disso, disponibiliza aos hóspedes variados serviços, como TV a cabo, wireless em todos os apartamentos e, em seu lobby, elevador, estacionamento privativo e circuito interno de TV, garantindo a segurança de seus clientes.

Embora seja um empreendimento recente, busca expandir-se, por meio da compra de terrenos próximos para a construção de uma área de lazer para os hóspedes, além de almejar o aumento no número de leitos a fim de atender à crescente demanda turística da cidade.

$\mathrm{O}$ fato de ser novo no mercado fez com que o Hotel X percebesse a necessidade de formar uma rede de cooperação com diversas empresas do setor turístico, incluindo outros hotéis da cidade, bares e restaurantes, entidades de captação de eventos e o governo do estado, por meio da Empresa Sergipana de Turismo (EMSETUR), da Fundação Municipal de Cultura Turismo e Esportes (FUNCAJU) e da Associação da Indústria de Hotéis (ABIH-SE). A necessidade de formar a rede explica-se também pela reduzida atuação do governo no setor. Segundo depoimento do entrevistado, embora o estado esteja investindo 
em turismo, ainda é um setor incipiente, fazendo-se necessária a atuação do setor privado para promover o desenvolvimento do turismo em Sergipe.

A formação da rede ocorreu por meio de reuniões realizadas mensalmente entre hoteleiros do estado e a EMSETUR. Nessas reuniões, começou-se a discutir a necessidade de formar uma rede de cooperação entre hotéis e demais empresas da rede turística, com a finalidade de aumentar a demanda turística da região por meio da divulgação do destino Sergipe em todo o País, tornando-o assim mais conhecido.

De acordo com o entrevistado, a formação da rede de cooperação proporciona vários benefícios, tais como a redução de custos de divulgação, uma vez que por meio da rede são eleitas uma ou duas pessoas para representar todos os participantes da rede, os quais viajam por todo o País divulgando tanto o turismo em Sergipe, quanto as empresas que compõem a rede; o aprendizado mútuo entre as empresas que compõem a rede; e o compartilhamento de informações. Para o entrevistado, a troca de informações é o maior benefício da rede, uma vez que, por meio dela, as empresas compartilham umas com as outras, por exemplo, inovações que foram aplicadas em seus negócios e deram certo, permitindo assim que os outros participantes possam usá-las em seus empreendimentos, oferecendo assim serviços de qualidade superior. Além disso, o sócio proprietário afirmou que, com a formação da rede, houve uma substituição do individualismo, bastante comum no setor turístico, por um enfoque coletivo, no qual todos buscam o alcance de um objetivo comum.

A colaboração entre as diversas empresas com o Hotel X, ocorre, informalmente, pela divulgação por meio de panfletos e folders, disponibilizados na recepção do hotel, ou por indicações realizadas pelo estabelecimento. Os parceiros que mais colaboram são os bares e restaurantes da orla, as locadoras de veículos, empresas de receptivos, responsáveis por passeios turísticos, agências de viagens e outros hotéis do estado.

A rede de cooperação entre os hotéis, as empresas do setor turístico e o governo vem alcançando seus objetivos, pois a demanda turística do estado está apresentando notável crescimento, como se pode verificar no depoimento do entrevistado:

Bom, a gente primeiro percebeu um aumento no número de hóspedes em Aracaju [...] principalmente no turismo de negócios [...] Hoje a gente tem uma ocupação hoteleira média de 70\%. Antes era de 40-50\%, tendo um aumento de 20-30\% de ocupação. Através desse trabalho que a gente vem fazendo as pessoas estão começando a descobrir um pouco mais [de] Sergipe. Não só os hoteleiros, mas também o governo, vêm dando apoio. É um trabalho de parceria, tanto dos órgãos públicos, quanto das empresas privadas. 


\subsection{O caso do Hotel Y}

No Hotel Y, entrevistou-se o gerente geral de 38 anos que cursa Marketing e Publicidade. Tem I2 anos de experiência no setor hoteleiro e atua há seis meses nesse hotel.

O empreendimento situa-se na praia dos Artistas, no início da orla de Atalaia, na cidade de Aracaju, conta com 62 funcionários e dispõe de setenta apartamentos classificados como 3 (três) estrelas, equipados com frigobar, TV a cabo e ar condicionado. Entre eles, há uma suíte nobre e seis executivas. Além de quartos luxuosos, o hotel oferece, ainda, serviços de qualidade - um diferencial em relação a outros hotéis: internet wireless livre, serviços de quarto por 24 horas, piscina com vista para o mar, sauna, café da manhã, restaurante, lavanderia, sala de ginástica, a fim de proporcionar o máximo conforto e tranquilidade para seus clientes.

Além disso, disponibiliza, em suas instalações, dois auditórios amplos, onde são realizados eventos, seminários e reuniões, atraindo os turistas que vêm à cidade para negócios.

Vale destacar ainda que o Hotel Y faz parte de uma das maiores redes hoteleiras do mundo, que se faz presente em oitenta países, é líder no mercado norte-americano e dispõe de mais de cem hotéis operantes em toda a América Latina. Para garantir a qualidade de seus serviços, essa rede submete cada uma das propriedades a uma inspeção com aproximadamente trezentos itens de controle diferenciados, estabelecidos com base nas respostas obtidas em outras pesquisas realizadas no mercado, as quais são realizadas anualmente pelos auditores de qualidade da rede.

Apesar de ser conhecido por turistas de diversas localidades e possuir uma marca bem estabelecida no mercado sergipano, o Hotel Y percebeu a necessidade de formar uma rede de cooperação com outros hotéis do estado, o governo de Sergipe e as empresas do setor turístico, com a finalidade de aumentar a demanda turística da região, visto que Sergipe ainda está "engatinhando" no turismo.

A criação do programa "Destino Sergipe" foi uma das principais campanhas realizadas por esse hotel juntamente com o governo do estado e a CVC. Esse programa tem por finalidade divulgar Sergipe em diversas localidades do País, mostrando suas características e qualidades e proporcionando dessa forma um aumento da demanda turística. Como mostra o depoimento do entrevistado:

\footnotetext{
[...] hoteleiros, em parceria com a EMSETUR, governo do estado [...] criamos um marketing chamado "Destino Sergipe", entregamos esse valor à CVC e ela tomou a iniciativa de contatar novas agências de publicidade [...] Criou-se uma propaganda publicitária muito forte no Sul e Sudeste, pra que as pessoas, justamente, possam conhecer nosso destino. Então todos os hotéis participam porque quem ganha não é um hotel só, mas toda a rede, porque se conhece Sergipe e passa a ter ele como um destino [...]
} 
A criação desse programa traz benefícios não apenas para os hotéis, mas também para as outras empresas do setor turístico e para o estado de Sergipe como um todo, uma vez que o aumento da demanda turística gera um aquecimento no setor e consequentemente resultados satisfatórios para a economia sergipana.

Além de almejar o aumento da demanda turística, o Hotel Y visa, por meio da rede de cooperação, a proporcionar um serviço de qualidade para que o turista seja recepcionado e atendido da melhor maneira, fazendo com que se sinta satisfeito e anseie retornar a Sergipe.

Entre os participantes mais atuantes da rede, o entrevistado destacou as empresas de receptivo, locadoras de veículos, restaurantes e operadoras turísticas. Essa cooperação se dá de forma bastante informal e indireta, não havendo contratos ou negociações pré-estabelecidas. O hotel possui um display, em que diversas empresas colocam seus panfletos ou folders. O único critério estabelecido para trabalhar em parceria com esse hotel é a qualidade do serviço, visto que é um dos principais objetivos do estabelecimento. A falta de qualidade ou algum erro que trouxer malefícios aos clientes faz com que o folder da empresa seja retirado imediatamente do display e a parceria seja invalidada.

\section{CONCLUSÃo}

O presente estudo foi desenvolvido com o intuito de analisar de que forma as redes de cooperação são utilizadas por empresas hoteleiras no município de Aracaju como ferramenta para a sobrevivência de seus negócios.

Com base na análise de dois casos, foi possível identificar uma atitude positiva dos empresários/gestores dos hotéis X e Y com relação ao trabalho em redes de cooperação com o intuito de compartilhar recursos e informações para que, assim, possam alcançar seu principal objetivo: o aumento da demanda turística do estado e a sobrevivência em mercado competitivo.

A formação da rede de cooperação trouxe vários benefícios para os componentes: aumento da demanda turística do estado, redução de custos com divulgação, possibilidade de aprendizagem mútua entre os componentes da rede e o compartilhamento de informações. Além disso, sentiu-se uma substituição do individualismo pela coletivização, em que todos os componentes da rede estão voltados para o alcance de um objetivo comum. Segundo Carrão (2004), em uma rede de cooperação existe maior ênfase no enfoque coletivo em substituição ao individual. A complexidade de uma rede origina-se da necessidade de facilitar a comunicação entre os membros e da tentativa de tornar compatíveis os objetivos da rede com os de seus componentes.

A análise dos casos permite concluir que a atuação em rede de cooperação vem possibilitando diversos benefícios para as empresas que consideram que, atualmente, seria praticamente impossível atuar de forma isolada e conseguir sobreviver no mercado competitivo. 


\section{REFERÊNCIAS}

ABIH. Perfil da hotelaria nacional. Disponível em: <http://www.abih.com.br/site.php>. Acesso em: I out. 2009.

AGÊNCIA DE NOTÍCIAS DE SERGIPE. Disponível em: <http://www.agencia.se.gov.br/noticias/ leitura/materia:I6885/numeros_do_ibge_e_seplan_revelam_forte_crescimento_do_ pib_sergipano>. Acesso em: I9 nov. 2009.

AMATO NETO, J. Redes de cooperação produtiva e clusters regionais: oportunidades para as pequenas e médias empresas. São Paulo: Atlas/Fundação Vanzolini, 2000.

ANDRADE, José Henrique de; ESCRIVÃo FILHO, Edmundo. Cluster e cooperação entre empresas: uma enquête (survey) com pequenos empreendimentos hoteleiros da região central do estado de São Paulo In: EGEPE — Encontro de Estudos sobre Empreendedorismo e Gestão de Pequenas Empresas, 3., 2003, Brasília. Anais... Brasília: uem/uel/unb, 2003. P. 626-639.

BALESTRIN, Alsones; REYes, Edgar; versCHOORE, Renato. O campo de estudo sobre redes de cooperação interorganizacional no Brasil. In: EnEO - Encontro de Estudos Organizacionais da ANPAD, 5., 2008, Belo Horizonte. Anais..., 2008. [P.?]

; vargas, Lilia Maria. A dimensão estratégica das redes organizacionais de PMEs: teorizações e evidências. RAC - Revista de Administração Contemporânea, Curitiba, v. 8, ed. especial, p. 203-228, 2004.

BARROS, A. J. P.; LEHFELD, N. A. s. Fundamentos de metodologia: um guia para a inicialização científica. São Paulo: McGraw-Hill, I986.

BATISTA, Paulo César de Souza; oliveira, Luiz Antônio Gouveia de. As pequenas empresas e as alianças estratégicas: tendências e oportunidades a partir da análise do pólo calçadista de Fortaleza In: ENANPAD — Encontro Nacional da Associação Nacional dos Programas de Pós-Graduação em Administração, 25., Campinas. Anais..., 200I. [P.?]

BECKER, Grace Vieira; BRASIL, Vinícius Sittoni. As relações entre competências interorganizacionais e o desempenho de redes de micro e pequenas empresas. Rio Grande do Sul, 2006.

BORGES, Cândido. Relacionamentos e competitividade: estudo com pMEs brasileiras aponta a importância das redes de contatos para a competitividade das empresas. $h \mathrm{sm}$ Management Update, São Paulo, n.ffl 20, [, p.?,] maio 2005.

BRITTO, Jorge. Elementos estruturais e conformação interna das redes de firmas: desdobramentos metodológicos, analíticos e empíricos, I999. [Tese?]

CÂNDIDo, Gesinaldo Ataíde. A formação de redes interorganizacionais como mecanismo para geração e vantagem competitiva e para promoção do desenvolvimento regional: O papel do estado e das políticas públicas neste cenário. Disponível em: <http://www.pronaf.gov. 
br/dater/arquivos/06_Formacao_de_redes.pdf>. Acesso em: I out. 2009.

CÂNDIDO, Índio; VIERA, Elenara. Gestão de hotéis: técnicas, operações e serviços. Caxias do Sul:

Educs, 2003.

CARRÃo, A. M. R. Cooperação entre empresas de pequeno porte. Revista de Administração

da USP, São Paulo, v. 39, n.ffl 2, p. 186-I85, abr./jun. 2004.

CURTIS Lali Felker de; HOFFMANN, Valmir Emil. Características determinantes de redes: um

estudo nos relacionamentos do setor hoteleiro das destinações turísticas de Gramado

e Canela (RS). Revista de Negócios, Blumenau, v. I4, n.ffl I p. 48-62, jan./mar. 2009.

Donaire, Denis; gaspar, Marcos Antonio; silva, Marcos Pereira da. A rede de negócios do

turismo: um estudo sobre suas características e implicações estratégicas. In: Revista

Turismo Visão e Ação - Eletrônica, Itajaí, v. II, n.ffl I, p. II2-I34, jan./abr. 2009.

EMSETUR. Relatório dos indicadores da hotelaria sergipana. Disponível em: < http://www.

emsetur.se.gov.br/relatorio_hotelaria_2008.pdf>. Acesso em: 4 out. 2009.

FERREIRA, Israel Junior; TEIXEIRA, Rivanda Meira. Redes de pequenas empresas: a aplicação

de uma tipologia em uma rede de supermercados. Revista de Administração Mackenzie,

São Paulo, v. 8, p. I28-152, 2007.

FERREIRA, Vicente da Rocha Soares; PASSADOR, Claudia Souza; PASSADOR, João Luiz. Produção

acadêmica sobre redes no Brasil. In: SIMPÓSIO DE GESTÃO DA INOVAÇÃO TECNOLÓGICA, 24.,

2006, Gramado. [Anais...?] [P.?]

hOCAYEN-DA-SILVA, Antônio João; teiXeira, Rivanda Meira. Análise dos relacionamentos

interorganizacionais em empresas do setor hoteleiro de Curitiba/PR: estudo comparativo de casos. Revista Brasileira de Pesquisa em Turismo, Rio de Janeiro, v. 3, n.ffl 2, p. 24-48, ago. 2009 .

HOFFMANN, v.e.; MOLINA-MORALES, F.X.; MARTINEZZ-FERNADEZ, M.T. Redes de empresas: uma tipologia para sua classificação. In: ENCONTRO DA ASSOCIAÇÃO NACIONAL DE PROGRAMAS DE PÓs-GRADUAÇÃO EM ADMINISTRAÇÃO, 28., 2004, Curitiba. Anais... Curitiba: ANPAD, 2004. [P.?] JORNAL DE TURISMO. Sergipe deve apresentar crescimento no turismo no segundo semestre.

Disponível em: <http://www.jornaldeturismo.com.br/index.php?format=html\&Itemi $\mathrm{d}=22 \&$ option=com_content\&id=27I49:turismosergipecrescimentosegundosemestre \&view=article\&change_font=medium $>$. Acesso em: 7 out. 2009.

LAKatos, E. M.; MARConi, M. A. Fundamento de metodologia científica. São Paulo: Atlas, I99I. LANIADO, R.N.; BAIARDI, A. A contribuição das redes na formação da cooperação empresarial - um estudo de caso. Organizações a Sociedade, Bahia, v.ıo, n.ffl 27, p. 6I-74, maio/ago. 2003. MIGuelLeto, Danielle Costa Reis. Organizações em rede. Disponível em: <http://www.ebape.

fgv.br/academico/asp/dsp_dit_resumos.asp?cd_artigo=702>. Acesso em: 3 out. 2009 . MORRISON, Alison; TEIXEIRA, Rivanda Meira. Desenvolvimento de empresários em empresas 
de pequeno porte do setor hoteleiro: processo de aprendizagem, competências e redes de relacionamento. Revista de Administração Contemporânea, São Paulo, v. 8, n.ffl i p. I05-I28, jan./mar. 2007.

NUNES, Flávia Furlan. Setor hoteleiro é promessa em contratações. Disponível em: $<$ http://www.administradores.com.br/noticias/setor_hoteleiro_e_promessa_em contratacoes $/ 25893>$. Acesso em: 5 out. 2009.

PETROCCHI, Mario. Hotelaria: planejamento e gestão. São Paulo: Pearson Prentice Hall, 2007. sANTos, Suzana Bierrenbach de Souza. Estratégias empresariais adotadas pela hotelaria em clusters turísticos no estado de São Paulo. São Paulo, Universidade Paulista — UNIP, 2007. SEDAI. Sedai lança quatro novas redes de cooperação. Disponível em: <http://www.sedai. rs.gov.br/noticiaView.php?idNoticia=638>. Acesso em: 6 out. 2009 .

SILVA, Teodomiro Fernandes da. Rede de cooperação entre pequenas empresas do setor turístico. Revista de Turismo y Patrimônio Cultural, Mato Grosso, v. 2, n.ffl 2, p. 267-279, 2004 .

TEIXEIRA, Rivanda Meira; MORRIson, A. Empreendedores no setor turístico: o caso das empresas hoteleiras de pequeno porte. In: EGEPE - Encontro de Estudos sobre Empreendedorismo e Gestão de pequenas empresas, 3., 2003, Brasília. Anais... Brasília: UNB/UEM/UEL, 2003. [P.?]

YIN, Robert K. Estudo de caso: planejamento e método. 2. ed. Porto Alegre: Bookman, 200I. 